\title{
Qualidade fisiológica de sementes de cultivares de feijão em função de densidades populacionais
}

\section{Physiological quality of seeds of bean cultivars in terms of population densities}

\author{
Hugo Tiago Ribeiro Amaro ${ }^{1 *}$; Andréia Márcia Santos de Souza David²; \\ Abner José de Carvalho²; Neiva Maria Batista Vieira3; \\ Ignacio Aspiazúz; Miquéias de Oliveira Assis ${ }^{4}$
}

\begin{abstract}
Resumo
Objetivou-se com este trabalho avaliar a qualidade fisiológica de sementes de diferentes cultivares de feijão em função de densidades populacionais. O experimento foi conduzido na Fazenda Experimental da Unimontes, em Janaúba, MG, com semeadura em março de 2011. O delineamento experimental utilizado foi em blocos casualizados, em esquema fatorial 4 x 5 , com quatro repetições. Os tratamentos consistiram em quatro cultivares de feijão de diferentes hábitos de crescimento (Ouro Vermelho, Ouro Negro, BRSMG Madrepérola e Manteigão Vermelho), e cinco densidades populacionais (100, 200, 300,400 e 500 mil plantas ha ${ }^{-1}$ ). As sementes foram avaliadas quanto ao teor de água, germinação e vigor (emergência de plântulas, índice de velocidade de emergência e envelhecimento acelerado). As cultivares Ouro Vermelho, Ouro Negro e BRSMG Madrepérola produzem sementes de melhor qualidade fisiológica, em relação a cultivar Manteigão Vermelho. O aumento da densidade de semeadura não afeta a qualidade fisiológica de sementes de cultivares de feijão, com exceção da Madrepérola, onde a

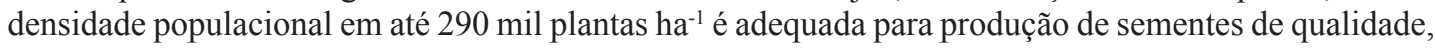
nas condições estudadas.
\end{abstract}

Palavras-chave: Phaseolus vulgaris L., populações de plantas, germinação, vigor

\begin{abstract}
The objective of this work was to evaluate the physiological quality of seeds of different cultivars of beans in terms of densities. The experiment was conducted at the Experimental Farm Unimontes in Janaúba, MG, with sowing in March 2011. The experimental design was a randomized block in factorial 4 x 5 with four replications. The treatments consisted of four bean cultivars of different growth habits (Ouro Vermelho, Ouro Negro, BRSMG Madrepérola and Manteigão Vermelho) and five densities $\left(100,200,300,400\right.$ and 500000 plants ha $\left.^{-1}\right)$. The seeds were evaluated for water content, germination and vigor tests (seedling emergence, speed of emergence index and accelerated aging). Cultivars Ouro Vermelho, Ouro Negro and BRSMG Madrepérola produce better quality seed physiological, relative to cultivate Manteigão Vermelhão. Increasing the seeding rate did not affect the physiological quality of seeds of bean cultivars, with the exception of Madrepérola, where the population density up to 290000 plants ha- ${ }^{-1}$ is suitable for production of quality seeds under the conditions studied.
\end{abstract}

Key words: Phaseolus vulgaris L., plant populations, germination, seeds force

${ }^{1}$ Eng $^{\mathrm{o}}$ Agr $^{\circ}$, Discente de Doutorado em Fitotecnia, Universidade Federal de Viçosa, UFV, Viçosa, MG. E-mail: htiagoamaro@ yahoo.com.br

2 Eng ${ }^{\text {os }}$ Agros $^{\text {s }}$, Profs. Drs. do Dept ${ }^{\text {o }}$ de Ciências Agrárias, Universidade Estadual de Montes Claros, UNIMONTES, Janaúba, MG. E-mail: andreia.david@unimontes.br; abner.carvalho@unimontes.br; aspiazu@gmail.com

${ }^{3}$ Eng $^{\mathrm{a}} \mathrm{Agr}^{\mathrm{a}}$, Prof ${ }^{\mathrm{a}} \mathrm{Dr}^{\mathrm{a}}$ do Instituto Federal de Educação, Ciência e Tecnologia do Sul de Minas Gerais, IFET, Machado, MG. E-mail: neiva@mch.ifsuldeminas.edu.br

${ }^{4}$ Discente do curso de Agronomia, UNIMONTES, Janaúba, MG. E-mail: mick_eafsal@hotmail.com

* Autor para correspondência 
Alimento tradicional e muito consumido pelos brasileiros, o feijão (Phaseolus vulgaris L.) representa uma das principais explorações agrícolas do país, desempenhando papel fundamental também na demanda por mão-de-obra. Em Minas Gerais, esta leguminosa é cultivada em todas as regiões, com os mais variados níveis tecnológicos e sistemas de produção (BORÉM; CARNEIRO, 2006).

Apesar da importância, o rendimento da cultura do feijão é considerado baixo. Dentre as causas, cita-se a baixa utilização de sementes de qualidade, uma vez que a quase totalidade dos agricultores reutiliza os grãos colhidos como sementes, fato este que contribui não só para obtenção de grãos de pior qualidade, como redução na produtividade (SENA et al., 2008). Esse fato tem gerado demanda por cultivares modernas de feijoeiro que atendam às exigências de manejo dos sistemas tecnificados, como a adequação de populações de plantas nas áreas de produção.

As cultivares de feijoeiro são diferenciadas em função do hábito de crescimento, característica fortemente correlacionada com a população de plantas (ALCÂNTARA et al., 1991). Para qualquer cultura, o conhecimento da combinação ótima da densidade de plantas e genótipo utilizado é essencial para que os fatores de produção sejam eficientemente aproveitados e o potencial produtivo da cultivar maximizado. Assim, o melhor arranjo de plantas depende das características intrínsecas da cultivar, como porte, hábito de crescimento e arquitetura de planta, bem como, do sistema de manejo da cultura (BEZERRA et al., 2009), fatores estes que irão determinar o grau de competição e o estádio em que ele será mais intenso entre as plantas.

Embora seja elevado o número de publicações que envolvem estudos de população de plantas e cultivares de diferentes tipos de crescimento sobre a produtividade do feijoeiro, ainda não existe consenso para o manejo correto desses parâmetros quando se avalia a qualidade fisiológica das sementes. Vieira e Yokoyama (2000) relatam que em populações muito baixas pode haver maior ocorrência de invasoras e desuniformidade na maturação, ocasionando queda significativa na qualidade da semente. Populações muito altas aumentam o custo com maior gasto de semente, bem como dificultam os tratos culturais e, em alguns casos, proporcionam, em função do tipo de hábito de crescimento da planta, queda na qualidade das sementes.

Assim, a utilização de sementes de desempenho superior é imprescindível para obtenção de uma população adequada de plantas por área, sendo que a variação na qualidade da semente ocorre em função de vários fatores externos e inerentes a própria planta. Diante do exposto, o objetivo desse trabalho foi avaliar a qualidade fisiológica de sementes de diferentes cultivares de feijão, em função de densidades populacionais.

O experimento foi conduzido na Fazenda Experimental da Universidade Estadual de Montes Claros - UNIMONTES, Janaúba, MG, com semeadura em março de 2011. A área experimental apresenta as seguintes coordenadas geográficas: $15^{\circ} 47^{\prime} 50^{\prime \prime} \mathrm{S}$ e $43^{\circ} 18^{\prime} 31^{\prime \prime} \mathrm{W}$, e altitude de $516 \mathrm{~m}$. O clima da região segundo classificação de Koppen é do tipo "AW" (tropical com inverno seco). As condições climáticas da região são representadas por temperaturas médias que variam de 21 a $25^{\circ} \mathrm{C}$, umidade relativa diária de 60 a $70 \%$ e precipitação média anual de $900 \mathrm{~mm}$.

O solo da área experimental foi classificado como Latossolo Vermelho eutrófico (EMBRAPA, 2006), cujas principais características químicas foram: $\mathrm{pH}$ : 5,4; M.O (dag $\left.\mathrm{kg}^{-1}\right)$ : 2,2; P $\left(\mathrm{mg} \mathrm{dm}^{-3}\right)$ : 7,$3 ; \mathrm{K}\left(\mathrm{mg} \mathrm{dm}^{-3}\right): 164 ; \mathrm{Al}\left(\mathrm{cmol}_{\mathrm{c}} \mathrm{dm}^{-3}\right): 0,2 ; \mathrm{H}+\mathrm{Al}$ $\left(\mathrm{cmol}_{\mathrm{c}} \mathrm{dm}^{-3}\right): 1,6 ; \mathrm{Ca}\left(\mathrm{cmol}_{\mathrm{c}} \mathrm{dm}^{-3}\right): 2,8 ; \mathrm{Mg}\left(\mathrm{cmol}_{\mathrm{c}}\right.$ $\left.\mathrm{dm}^{-3}\right) ; 0,7$;B $\left(\mathrm{cmol}_{\mathrm{c}} \mathrm{dm}^{-3}\right): 3,9 ; \mathrm{t}\left(\mathrm{cmolc} \mathrm{dm}^{-3}\right): 4,1$ ; T $\left(\mathrm{cmolc} \mathrm{dm}^{-3}\right): 5,6 ; \mathrm{m}(\%): 4$ e V (\%): 70,0.

O delineamento experimental utilizado foi em blocos casualizados, em esquema fatorial $4 \times 5$, com quatro repetições. Os tratamentos consistiram em quatro cultivares de feijão de diferentes tipos de crescimento (Ouro Vermelho, Ouro Negro, 
BRSMG Madrepérola e Manteigão Vermelho), e cinco densidades populacionais $(100,200,300,400$ e 500 mil plantas ha $^{-1}$ ).

A cultivar Ouro Vermelho apresenta grãos do grupo comercial vermelho, com ciclo cultural de 80-90 dias, porte semiprostrado e tipo de hábito de crescimento II/III (indeterminado). A cultivar Ouro Negro apresenta grãos do grupo comercial preto, ciclo de 80-100 dias, hábito de crescimento tipo III (indeterminado) e porte prostrado (PAULA JUNIOR et al., 2010). A BRSMG Madrepérola apresenta grãos do grupo comercial carioca, ciclo de 80 dias, porte prostrado, hábito de crescimento tipo III (indeterminado), enquanto a cultivar Manteigão Vermelho apresenta grãos do grupo comercial Manteigão, com coloração vermelha, ciclo de 80-90 dias, hábito de crescimento tipo II (indeterminado) e porte semi-ereto.

Cada parcela foi composta por 6 fileiras de 5 metros de comprimento, espaçadas de $0,5 \mathrm{~m}$ entre si, perfazendo área total de $15 \mathrm{~m}^{2}$, sendo utilizada como área útil as plantas localizadas na terceira e quarta fileiras de cada parcela.

O preparo do solo foi convencional, constando de uma aração e duas gradagens, realizadas em pré-semeadura. Baseado nos resultados das análises químicas das amostras coletadas na área experimental, verificou-se que não havia a necessidade de aplicação de calcário. A adubação do feijoeiro foi baseada na recomendação oficial para o Estado de MG para o nível 3 de tecnologia (CHAGAS et al., 1999) e constou da aplicação de $375 \mathrm{~kg} \mathrm{ha}^{-1}$ da formulação 04-30-10 na semeadura, mais $40 \mathrm{~kg} \mathrm{ha}^{-1}$ de $\mathrm{N}$ em cobertura, fonte uréia, aplicados via solo em forma de filete contínuo durante o estádio $\mathrm{V}_{3}-\mathrm{V}_{4}$ da cultura. Além disso, foi realizada uma aplicação via foliar de $40 \mathrm{~g} \mathrm{ha}^{-1} \mathrm{de}$ molibdênio, utilizando o molibdato de sódio como fonte. Antes da semeadura, as sementes foram tratadas com a mistura dos fungicidas carboxin e thiram na dosagem de $300 \mathrm{ml} 100 \mathrm{~kg}^{-1}$ de sementes.

A semeadura foi feita com uso de semeadoras manuais, adotando-se a densidade de semeadura ideal com auxílio de réguas de madeira marcadas para cada densidade pré-determinada pelos tratamentos. As densidades foram suficientes para, após o desbaste, realizado aos 10 DAE (dias após a emergência), obterem- se as populações desejadas. O controle das plantas daninhas foi realizado com a aplicação de uma mistura em tanque dos herbicidas fomesafen e fluazifop-p-butyl na dosagem de 125 $\mathrm{g} \mathrm{ha}^{-1}$, aos 25 dias após a emergência. Utilizou-se irrigação complementar por aspersão convencional, fornecendo lâmina de $500 \mathrm{~mm}$ até o estádio de maturação fisiológica e senescência das plantas, com um turno de rega de três dias. $\mathrm{O}$ experimento foi constantemente monitorado onde todas as medidas fitossanitárias foram tomadas de acordo com a necessidade da cultura.

Realizou-se manualmente a colheita das plantas pertencentes à área útil de cada parcela, submetendo-as à trilha, também manualmente, para a obtenção das sementes. Devido às diferenças de épocas de maturação que ocorreram entre as cultivares, realizou-se a colheita das parcelas assim que as mesmas atingiram a maturação, caracterizada quando as vagens perderam sua pigmentação e começaram a secar. As sementes foram limpas e secadas, e posteriormente levadas ao Laboratório de Análise de Sementes da UNIMONTES, campus Janaúba - MG para avaliação da qualidade fisiológica, por meio dos seguintes testes e/ou determinações:

O teor de água foi determinado, conforme metodologia prescrita nas Regras para Análise de Sementes - RAS (BRASIL, 2009).

Para o teste de germinação foram utilizadas quatro repetições de 50 sementes, distribuídas uniformemente sobre papel germitest na forma de rolo, umedecido com água destilada, na proporção de 2,5 vezes a sua massa inicial. Os rolos foram colocados em germinador previamente regulado à temperatura de $25^{\circ} \mathrm{C}$. As contagens das plântulas normais foram feitas aos 5 (primeira contagem 
de germinação) e 9 dias após a semeadura e os resultados expressos em porcentagem conforme as RAS (BRASIL, 2009).

O teste de emergência de plântulas foi conduzido sob condições de laboratório, utilizando-se como substrato areia lavada. As sementes foram semeadas a uma profundidade de $3 \mathrm{~cm}$, em bandejas plásticas, contendo o substrato umedecido com quantidade de água equivalente a $60 \%$ da capacidade de retenção (BRASIL, 2009). Foram utilizadas quatro repetições de 50 sementes e os resultados foram obtidos pelo número de plântulas normais emersas, determinado por ocasião do nono dia após a instalação do teste, sendo os resultados expressos em porcentagem.

$O$ índice de velocidade de emergência foi conduzido em conjunto com o teste de emergência de plântulas, anotando-se diariamente, no mesmo horário, o número de plântulas que apresentaram alça cotiledonar visível. Ao final do teste, foi calculado o índice de velocidade de emergência, empregando-se a fórmula proposta por Maguire (1962).

Para o envelhecimento acelerado, foram distribuídas 200 sementes por tratamento sobre a superfície de uma tela metálica fixada e suspensa no interior de caixa plástica - gerbox, contendo 40 $\mathrm{mL}$ de água destilada, mantida a $41{ }^{\circ} \mathrm{C}$ e $100 \%$ de umidade relativa, por 72 horas em um germinador (MARCOS FILHO, 1999). Decorrido esse período, as sementes foram retiradas da câmara e postas para germinar nas mesmas condições descritas para o teste de germinação, no qual determinou-se a porcentagem de plântulas normais no quinto dia após a instalação do teste.

Os dados não foram transformados por terem atendido às pressuposições dos testes de normalidade e de homogeneidade, sendo submetidos à análise de variância. Os efeitos das densidades populacionais foram estudados por análise de regressão, escolhendo-se os modelos adequados para representá-los em função do seu comportamento biológico, da significância dos coeficientes do modelo e do valor do coeficiente de determinação $\left(\mathrm{R}^{2}\right)$ e os efeitos das cultivares foram estudados pelo teste de Tukey a 5\% de significância.

A análise de variância dos dados revelou que houve efeito significativo da fonte de variação cultivar $(\mathrm{CV})$ sobre todas as características avaliadas. A densidade de semeadura (D) e a interação CV x D foram significativas para germinação de sementes e índice de velocidade de emergência.

Analisando o teor de água das sementes como procedimento inicial, observa-se que os resultados apresentaram comportamento diferenciado entre as cultivares (Tabela 2). Os maiores valores foram encontrados nas cultivares Ouro Vermelho e Ouro Negro, enquanto as cultivares Madrepérola e Manteigão Vermelho não diferiram entre si. Entretanto, observa-se que houve variação entre 9,6 e $11,5 \%$ nos teores de água das cultivares. Vale ressaltar que esses valores estão dentro dos padrões considerados ideais para colheita e armazenamento de sementes de feijão (VIEIRA; YOKOYAMA, 2000).

Odesdobramentoda interação CVx D, estudandose os efeitos de cultivares dentro de cada densidade de semeadura, revelou que as cultivares Ouro Vermelho, Ouro Negro e Madrepérola apresentaram maiores porcentagens de germinação em todas as densidades estudadas, atendendo aos padrões mínimos exigidos para a produção e comercialização de sementes de feijão, ao constatarem valores acima de $80 \%$ de germinação (Tabela 1). Segundo a legislação vigente, as sementes são caracterizadas de acordo com a sua categoria, sendo considerada germinação mínima de $70 \%$ para sementes básicas e $80 \%$ para sementes certificadas (C1 e C2) ou não certificadas (S1 e S2) de primeira e de segunda gerações (BRASIL, 2005). No entanto, verificou-se que as sementes originadas da cultivar Manteigão Vermelho apresentaram valores inferiores ao padrão mínimo exigido comercialmente para todas as categorias de sementes. 
Tabela 1. Resultados médios das variáveis germinação de sementes e índice de velocidade de emergência de plântulas de cultivares de feijão semeadas em diferentes densidades populacionais. Janaúba, MG. 2012.

\begin{tabular}{|c|c|c|c|c|c|c|c|}
\hline \multirow[b]{2}{*}{ Cultivares } & \multicolumn{5}{|c|}{ Densidades populacionais (mil plantas ha-1) } & \multirow{3}{*}{$\mathrm{X}$} & \multirow[b]{2}{*}{ ER } \\
\hline & 100 & 200 & 300 & 400 & 500 & & \\
\hline \multicolumn{7}{|c|}{ Germinação (\%) } & \\
\hline Ouro Vermelho & $96^{\mathrm{A}}$ & $96^{\mathrm{A}}$ & $96^{\mathrm{A}}$ & $96^{\mathrm{A}}$ & $96^{\mathrm{A}}$ & 96,0 & $\begin{array}{cc}---- \\
-\cdots\end{array}$ \\
\hline Ouro Negro & $91^{\mathrm{A}}$ & $93^{\mathrm{AB}}$ & $94^{\mathrm{A}}$ & $96^{\mathrm{A}}$ & $97^{\mathrm{A}}$ & 94,2 & 1 \\
\hline Madrepérola & $87^{\mathrm{B}}$ & $87^{\mathrm{B}}$ & $92^{\mathrm{A}}$ & $86^{\mathrm{B}}$ & $80^{\mathrm{B}}$ & 85,6 & 2 \\
\hline Manteigão Verm & $41^{\mathrm{C}}$ & $52^{\mathrm{C}}$ & $43^{\mathrm{B}}$ & $50^{\mathrm{C}}$ & $48^{\mathrm{C}}$ & 46,8 & --- \\
\hline \multicolumn{8}{|c|}{ Indice de velocidade de emergência } \\
\hline Ouro Vermelho & $14,9^{\mathrm{A}}$ & $14,8^{\mathrm{A}}$ & $14,6^{\mathrm{A}}$ & $14,8^{\mathrm{A}}$ & $12,9^{\mathrm{A}}$ & 14,4 & ---- \\
\hline Ouro Negro & $13,3^{\mathrm{A}}$ & $11,9^{\mathrm{B}}$ & $13,4^{\mathrm{A}}$ & $12,6^{\mathrm{A}}$ & $12,9^{\mathrm{A}}$ & 12,8 & ---- \\
\hline Madrepérola & $13,9^{\mathrm{A}}$ & $13,1^{\mathrm{AB}}$ & $13,1^{\mathrm{A}}$ & $11,4^{\mathrm{A}}$ & $10,7^{\mathrm{A}}$ & 12,4 & 3 \\
\hline Manteigão Verm & $4,0^{\mathrm{B}}$ & $4,8^{\mathrm{C}}$ & $4,4^{\mathrm{B}}$ & $6,4^{\mathrm{B}}$ & $5,0^{\mathrm{B}}$ & 4,9 & ---- \\
\hline
\end{tabular}

$\mathrm{X}=$ média

Letras maiúsculas distintas na coluna, diferem entre si pelo teste Tukey em nível de 5\% de probabilidade.

$\mathrm{ER}=$ Equação de Regressão

1: $\hat{Y}=89,57500^{*}+0,01675^{*} x ; R^{2}=74,1 \%$

2: $\hat{Y}=71,40000 *+0,13392 * x-0,00023 * x^{2} ; R^{2}=91,7 \%$

3: $\hat{Y}=14,67550 *-0,00802 * x ; R^{2}=68,8 \%$

* significativo em nível de $5 \%$ pelo teste "t"

Fonte: Elaboração dos autores.

As sementes das cultivares de hábito de crescimento indeterminado, dos tipos II/III e III (Ouro Vermelho, Ouro Negro e Madrepérola) apresentaram valores superiores na germinação quando comparado a cultivar de hábito do tipo II, de porte semi-ereto (Manteigão Vermelho). Este resultado pode ser atribuído à constituição genética da própria cultivar, sendo este material pouco explorado em programas de melhoramento.

Ressalta-se também que, em função da preferência comercial e consequente predominância de cultivares de crescimento indeterminado (principalmente dos tipos III e II/III) entre os agricultores nas últimas décadas, os trabalhos de pesquisa abordando melhoramento genético, manejo fitotécnico e principalmente tecnologia de produção de sementes, nesse período, foram voltados na maioria das vezes para cultivares desses grupos. Diante disso, cultivares desse grupo podem expressar melhores respostas em relação às outras, o que possivelmente explica os menores resultados de germinação da cultivar Manteigão Vermelho, em todas as densidades de semeadura (Tabela 1).
Assim, estudos são necessários para a validação das tecnologias atualmente recomendadas para a cultura, inclusive no que diz respeito ao arranjamento espacial de plantas que conduz à maximização da produtividade (VALÉRIO; ANDRADE; FERREIRA, 1999), bem como para a produção de sementes de qualidade.

O desdobramento da interação CV x D, avaliando os efeitos das densidades populacionais dentro de cada cultivar, revelou efeitos significativos apenas para as cultivares Ouro Negro e Madrepérola (Tabela 1). Para a cultivar Ouro Negro, os resultados de germinação se enquadraram numa equação de regressão de comportamento linear, com incremento na germinação das sementes à medida que aumentava a densidade de semeadura. Entretanto, ressalta-se que, apesar de significativa, o aumento da germinação em resposta às densidades populacionais foi de pouca magnitude, variando entre 91 e $97 \%$.

Já para a cultivar Madrepérola, a germinação seguiu um comportamento quadrático (Tabela 
1), onde o aumento da densidade de semeadura de até 290 mil plantas ha $^{-1}$, segundo o modelo ajustado, provocou incremento na germinação, atingindo o percentual máximo de $90 \%$. A partir dessa densidade, houve reduções nos valores, sendo verificado $80 \%$ de germinação na densidade de 500 mil plantas ${ }^{-1}$. Certamente este resultado está associado a maior competição intraespecífica e maior acamamento provocado pelo adensamento da lavoura, prejudicando a qualidade das sementes. De uma maneira geral, com o aumento do número de plantas por área existe distribuição diferenciada de luminosidade nos vários estratos do dossel vegetativo da cultura, proporcionando assim, alteração na utilização da energia solar, modificando a relação fonte/dreno das plantas (ROCHA, 1991), podendo refletir também no desempenho das sementes.

O desdobramento da interação $\mathrm{CV}$ x D, avaliando os efeitos das cultivares dentro de cada densidade populacional, revelou que as cultivares Ouro Negro, Ouro Vermelho e Madrepérola apresentaram maiores índices de velocidade de emergência em relação a cultivar Manteigão Vermelho, independente da densidade de semeadura (Tabela 1).

Já verificando o comportamento das densidades de plantio dentro de cada cultivar, observa-se diferenças significativas apenas para a cultivar Madrepérola, onde o aumento da densidade de semeadura provocou redução no índice de velocidade de emergência de plântulas. Na densidade de 100 mil plantas $\mathrm{ha}^{-1}$, foram observados índices de 13,9; encerrando em 10,7 na densidade de 500 mil plantas ha $^{-1}$ (Tabela 1).

Vazquez; Carvalho e Borba (2008) avaliando os efeitos de reduções na população de plantas sobre a produtividade e qualidade fisiológica de sementes de soja, verificaram que variações na população de plantas não provocaram alterações na porcentagem de germinação e de envelhecimento acelerado das cultivares avaliadas. Resultados contrários, entretanto, foram observados por Crusciol et al. (2002), verificando acréscimos na qualidade fisiológica de sementes com o aumento da população de plantas.

Os resultados obtidos nos testes de emergência de plântulas e envelhecimento acelerado demonstraram efeito significativo apenas para cultivares (Tabela 2). Para emergência de plântulas, as cultivares de hábito de crescimento tipo II/III e tipo III produziram sementes de melhor desempenho em relação a cultivar do tipo de crescimento II (Manteigão Vermelho). Esse comportamento foi semelhante ao observado no teste de germinação, certamente em função das características intrínsicas das cultivares, como o menor potencial de competição por fotoassimilados nas cultivares de hábito determinado em relação à de hábito indeterminado.

Tabela 2. Valores médios, em porcentagem, do teor de água de sementes, emergência de plântulas e envelhecimento acelerado de cultivares de feijão. Janaúba, MG, 2012.

\begin{tabular}{lcccc}
\hline \multirow{2}{*}{ Variável } & \multicolumn{4}{c}{ Cultivares } \\
\cline { 2 - 5 } & Ouro Vermelho & Ouro Negro & Madrepérola & Manteigão Vermelho \\
\hline Teor de água & $11,5 \mathrm{a}$ & $11,0 \mathrm{a}$ & $10,0 \mathrm{bc}$ & $9,6 \mathrm{c}$ \\
Emergência de plântulas & $92,0 \mathrm{a}$ & $98,0 \mathrm{a}$ & $92,0 \mathrm{a}$ & $52,0 \mathrm{~b}$ \\
Envelhecimento acelerado & $72,0 \mathrm{a}$ & $74,0 \mathrm{a}$ & $71,0 \mathrm{a}$ & $45,0 \mathrm{~b}$ \\
\hline
\end{tabular}

Médias seguidas por letras diferentes na linha, diferem estatisticamente entre si pelo teste Tukey, a 5\% de probabilidade.

Fonte: Elaboração dos autores. 
Em relação ao envelhecimento acelerado, verifica-se resposta semelhante à emergência de plântulas, evidenciando superioridade no vigor das cultivares Ouro Vermelho, Ouro Negro e Madrepérola (Tabela 2). Sementes mais vigorosas possibilitam um crescimento inicial mais rápido de plântulas, com maior captura de luz e melhor utilização dos recursos do ambiente. Nesse sentido, mesmo após o estresse provocado pelo envelhecimento, essas cultivares apresentaram elevado potencial fisiológico das sementes, comparativamente à cultivar Manteigão Vermelho.

Como relatado, os resultados de emergência de plântulas e envelhecimento acelerado não foram influenciados pelas densidades de semeadura, sendo essas características mais influenciadas pelas condições ambientais do que por densidades populacionais. Trabalhos abordando o efeito da população de plantas sobre a qualidade fisiológica de sementes são escassos e, de certa forma, contraditórios. Objetivando avaliar a qualidade fisiológica de sementes de cultivares de soja em diferentes densidades populacionais, Vazquez; Carvalho e Borba (2008) concluíram que variações na população de plantas de soja não interferem na qualidade fisiológica de sementes.

De maneira geral, são essenciais os conhecimentos sobre as alterações morfofisiológicas das cultivares e as respostas sobre o desempenho fisiológico de sementes, quando submetidas a diferentes densidades populacionais, uma vez que essas cultivares necessitam de práticas culturais adequadas, assegurando maior confiabilidade na recomendação de novas cultivares, aumentando a adoção desses materiais por parte dos agricultores.

Diante do resultados, conclui-se que as cultivares Ouro Vermelho, Ouro Negro e BRSMG Madrepérola produzem sementes de melhor qualidade fisiológica, em relação a cultivar Manteigão Vermelho.

O aumento da densidade de semeadura não afeta a qualidade fisiológica de sementes de cultivares de feijão, com exceção da Madrepérola, onde a densidade populacional em até 290 mil plantas ha ${ }^{-1}$ é adequada para produção de sementes de qualidade, nas condições estudadas.

\section{Agradecimentos}

À Fundação de Amparo à Pesquisa do Estado de Minas Gerais (FAPEMIG) e à Universidade Estadual de Montes Claros (UNIMONTES), pelo apoio financeiro e técnico para o desenvolvimento desta pesquisa.

\section{Referências}

ALCÂNTARA, J. P.; RAMALHO, M. A. P.; ABREU, A. F. B. T.; SANTOS, J. B. Avaliação de cultivares de feijoeiro (Phaseolus vulgaris L.) em diferentes densidades de semeadura e condições de ambiente. Ciência e Prática, Lavras, v. 15, n. 4, p. 331-428, 1991.

BEZERRA, A. A de C.; TÁVORA, F. J. A. F.; FREIRE FILHO, F. R.; RIBEIRO, V. Q. Características de dossel e de rendimento em feijao-caupi ereto em diferentes densidades populacionais. Pesquisa Agropecuária Brasileira, Brasília, v. 44, n. 10, p. 1239-1245, out. 2009.

BORÉM, A.; CARNEIRO, J. E. S. A cultura. In: VIEIRA, C.; PAULA JÚNIOR, T. J. de; BORÉM, A. Feijão. 2. ed. Viçosa: UFV, 2006. p. 14-18.

BRASIL. Ministério da Agricultura, Pecuária e Abastecimento. Instrução Normativa 25/2005. Ministério da Agricultura, Pecuária e do Abastecimento (Anexo V Padrões para produção e comercialização de sementes de feijão). Brasília, DF: SNAD/DNDN/CLAV: D.O.U, 20 dez. 2005, Seção 1, p. 18.

Ministério da Agricultura, Pecuária e Abastecimento. Regras para análise de sementes. Brasília: DNDV/CLAV, 2009. 365 p.

CHAGAS, J. M.; BRAGA, J. M.; VIEIRA, C.; SALGADO, L. T.; JUNQUEIRANETO, A.; ARAÚJO, G. A. A.; ANDRADE, M. J. B.; LANA; R. M. Q.; RIBEIRO, A. C. Feijão. In: RIBEIRO, A. C.; GUIMARÃES, P. T. G.; ALVAREZ V. V. H. (Ed.). Recomendações para o uso de corretivos e fertilizantes em Minas Gerais: $5^{\text {a }}$ aproximação. Viçosa, MG: Comissão de Fertilidade do Solo do Estado de Minas Gerais, 1999. p. 306-307.

CRUSCIOL, C. A. C.; LAZARINI, E.; BUZO, C. L.; SÁ, M. E. de. Produção e qualidade fisiológica de sementes de soja avaliadas na semeadura de inverno. Scientia Agricola, Piracicaba, v. 59, n. 1, p. 75-96, 2002. 
EMPRESA BRASILEIRA DE PESQUISA AGROPECUÁRIA - EMBRAPA. Sistema brasileiro de classificação de solos. 2. ed. Rio de Janeiro: Embrapa Solos, 2006. 306 p.

MAGUIRE, J. D. Speed of germination-aid in selection and evaluation for seedling emergence and vigor. Crop Science, Madison, v. 2, n. 1 p. 176-177, 1962.

MARCOS FILHO, J. Teste de envelhecimento acelerado. In: KRZYZANOWSKI, F. C.; VIEIRA, R. D.; FRANÇA NETO, J. B. (Ed.). Vigor de sementes: conceitos e testes. Londrina: ABRATES, 1999. cap. 3, p. 1-24.

PAULA JÚNIOR, T. J. de; CARNEIRO, J. E de S.; VIEIRA, R. F.; ABREU, A. de F. B.; RAMALHO, M. A. P.; PELOSO, M. J. del.; TEIXEIRA, H. Cultivares de feijão-comum para Minas Gerais. Belo Horizonte: EPAMIG, 2010. 39 p.

ROCHA, J. A. M. Produção de feijoeiro (Phaseolus vulgaris L.) cultivado em populações variáveis quanto ao número e ao arranjamento de plantas. 1991. Dissertação (Mestrado em Agronomia, Fitotecnia) - Escola Superior de Agricultura Luiz de Queiroz. Universidade de São Paulo, Piracicaba.
SENA, M. R.; ABREU, A de F. B.; RAMALHO, M. A. P.; BRUZI, A. T. Envolvimento de agricultores no processo seletivo de novas linhagens de feijoeiro. Ciência e Agrotecnologia, Lavras, v. 32, n. 2, p. 407-412, mar./abr., 2008.

VALÉRIO, C. R.; ANDRADE, M. J. B. de; FERREIRA, D. F. Comportamento das cultivares de feijão Aporé, Carioca e Pérola em diferentes populações de plantas e espaçamentos entre linhas. Ciência e Agrotecnologia, Lavras, v. 23, n. 3, p. 515-528, jul./set. 1999.

VAZQUEZ, G. H.; CARVALHO, N. M.; BORBA, M. M. Z. Redução na população de plantas sobre a produtividade e a qualidade fisiológica da semente se soja. Revista Brasileira de Sementes, v. 30, n. 2, p. 1-11, 2008.

VIEIRA, E. H. N.; YOKOYAMA, M. Colheita, processamento e armazenamento. In: VIEIRA, E. H. N.; RAVA, C. A. Sementes de feijão: produção e tecnologia. Santo Antônio de Goiás: Empresa Brasileira de Pesquisa Agropecuária, 2000. p. 233-248. 